\title{
Physiological Changes of Salivary Parameters in Patients with End Stage Renal Failure \\ Mohammed Hadi
}

B.D.S - Master Student, Department of Basic Science, College of Dentistry, University of Baghdad..

Khalid H. Gathwan

Ph.D. - Professor, Department of Basic Science, College of Dentistry, University of Baghdad

\begin{abstract}
Background:Many oral diseases were recorded in ESRD patients including as gingivitis, tooth mobility, xerostomia, ammonia-like smell, mucosal pallor and lesions, malocclusion and an increased risk of dental erosion. Salivary changes among ESRD patients might be attributed to renal failure, use of multiple medications, vomiting, depressive mood and low oral health hygiene.

Aim of study: to assess the salivary changes of patients with end stage renal disease.To determine whether there is changes in salivary compositions and biochemical parameters (urea, creatinine, salivary $\mathrm{PH}$ ) of patients with end stage renal failure.To find whether there is change in salivary trace element (zinc, copper).To identify whether there is change in salivary electrolyte (sodium, potassium, calcium, phosphate).Determine whether there is a change in salivary enzymes (amylase).

Subjects, Materials and Methods:A cross sectional study carried out in two dialysis centers in Baghdad (Al-Khadhimya Teaching Hospital and Al-Karamah Teaching Hospital) through a period from $1^{\text {st }}$ of March to end of $30^{\text {th }}$ of July, 2015 on convenient sample of 64 patients with end stage renal diseases and on 64 healthy controls. Salivary samples were collected by the researcher at the end of dialysis. Saliva was collected using the standard way of collection. The samples controlled to avoid drooling or swallowing. Whole saliva was collected under resting conditions in a quiet room. Duration was between 0900 and noon at least $1 \mathrm{~h}$ after dialysis. Each patient was asked to chew a piece of Arabic gum (0.5-0.7 gm) for one minute, all saliva was removed expectoration, chewing was continued for five minutes with the same piece of gum and saliva was collected in sterile screw capped bottle. Salivary urea and Amylase were analyzed by specific kits, while slivary PH was tested by a hand-held pH meter. Salivary trace elements of saliva were analyzed at the Poisoning Consultation Center/Specialized Surgeries hospital by flame atomic absorption following standardized procedure.

Results: Mean age of ESRD patients was $50.1 \pm 14.9$ years, males were more than females. No significant difference was observed between patients and controls regarding age and gender.There was a highly significant difference in salivary Potassium, Sodium, Calcium, Copper, Urea and Amylase levels between ESRD patients and controls $(p<0.001)$. There was a significant difference in salivary Zinc level between ESRD patients and controls $(p=0.02)$. There was a significant association between increased age of ESRD patients and HT $(p=0.04)$. A significant association was observed between HT among ESRD patients and high salivary Zinc level $(p=0.008)$.

Conclusion: Abnormal high Salivary Urea concentration in ESRD patients are associated with or was high and it was a significant predictor of ESRD. This study showed that salivary minerals (Potassium, Sodium, Calcium and Copper) were more likely to be reduced in ESRD patients undergone hemodialysis.
\end{abstract}

KEYWORDS

Salivary Parameters, Renal Failure.

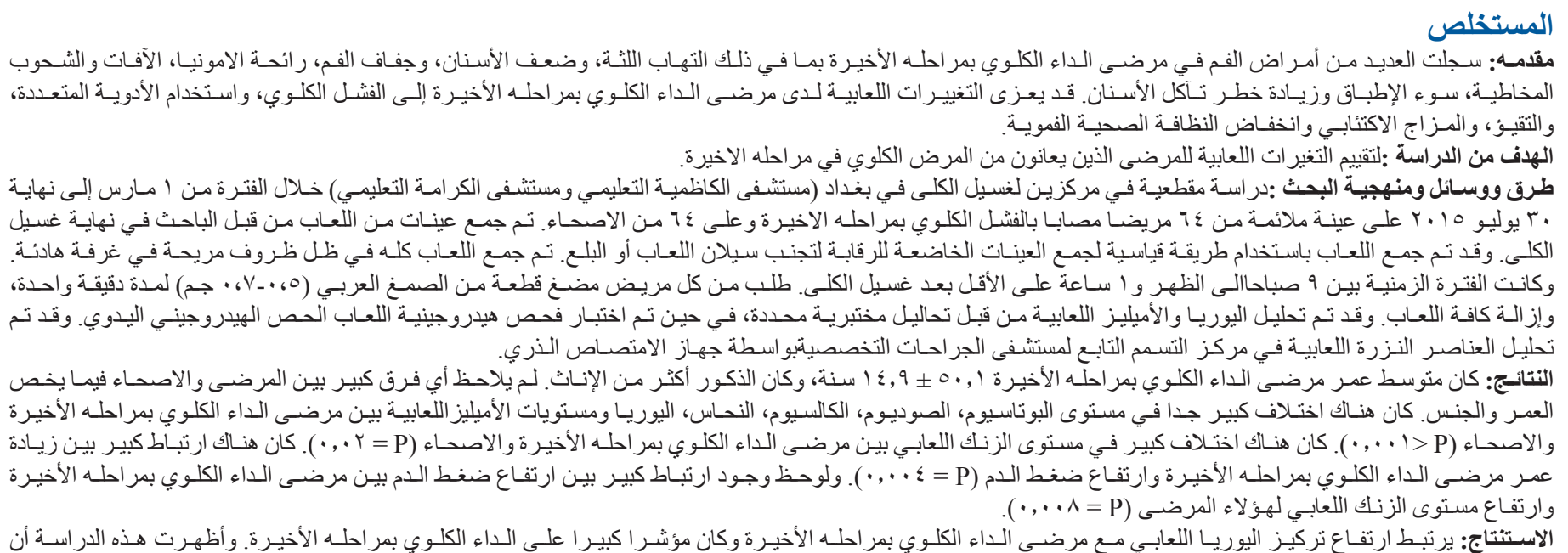

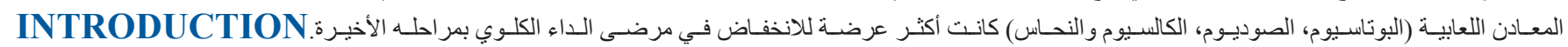

Renal failure is a process in which the nephrons lose their functional capacity and failure in filtering waste products caused by many causes. The renal failure is mostly reversible but chronic renal failure (CRF) had a progressive course deteriorated towards end stage renal disease (ESRD), although the cause of

the initial nephropathy disappears ${ }^{(1)}$.

The saliva is a unique biological fluid that described as the "mirror of the body". It is produced by salivary glands and composed mainly of water (98\%) and $2 \%$ other compounds (minerals, electrolytes, etc.) (2). Many oral diseases were recorded among ESRD 
patients as gingival inflammation, tooth mobility, dry mouth, bad smell, mucosal changes and high liability for dental abrasion. Salivary changes among ESRD patients might be attributed to renal insufficiency, use of medications, vomiting, depressive mood and low health hygiene ${ }^{(3,4)}$.

There is no wide researches on long term effect of dialysis on oral health and saliva, although, many literatures reported the harmful effect of renal transplant on oral health ${ }^{(5)}$.

The main symptom of renal failure is an electrolyte disturbance and break in albumin-creatinine ratio that affect directly on saliva. Some literatures reported the significance of oxidative stress during dialysis in responsibility of salivary changes ${ }^{(6)}$.

\section{SUBJECT, MATERIALS AND METHODS}

The study included sixty four patients with end stage renal diseases diagnosed by specialist physician in Internal Medicine and treated regularly with dialysis. The patients were selected from two dialysis centers in Baghdad (Al-Khadhimya Teaching Hospital and Al-Karamah Teaching Hospital) as a convenient sample.

The study was carried out for period from $1^{\text {st }}$ of March to end of $30^{\text {th }}$ of July, 2015.The inclusion criteria of the study were end stage renal diseases patients with dialysis duration more than one month. The exclusion criteria were mental disorder, hematological disease, diabetes mellitus and use of drugs interfering with salivary metabolism. The data was collected by direct interview and fulfilling a prepared questionnaire. The questionnaire included the following information:

1.Sociodemographic characteristics: Age and gender.

2.Clinical findings: Hemodialysis duration and hypertension.

3. Salivary parameters investigation results: Salivary

Potassium, Sodium, Calcium, Copper, Zinc, PH, Urea and Amylase results.

Control subjects were recruited from Baghdad Medical City, private clinics and some friends from systemically healthy people but that required treatment due to dental problems. All controls had no systemic illnesses, including diabetes mellitus and renal or liver disease.Duration of dialysis was 4 hours per session, with $300-350 \mathrm{~mL} /$ minute blood flow rate or with a dialysate flow of $500 \mathrm{~mL} /$ minute. Patients with active infection or that were on medication influencing salivary flow rate, such as antidepressant drugs, were excluded.

\section{Study design}

A cross sectional study carried out on patients and controls to asseدss the relationship between salivary parameters and ESRD patients as shown in figure1.

\section{Cross sectional study}
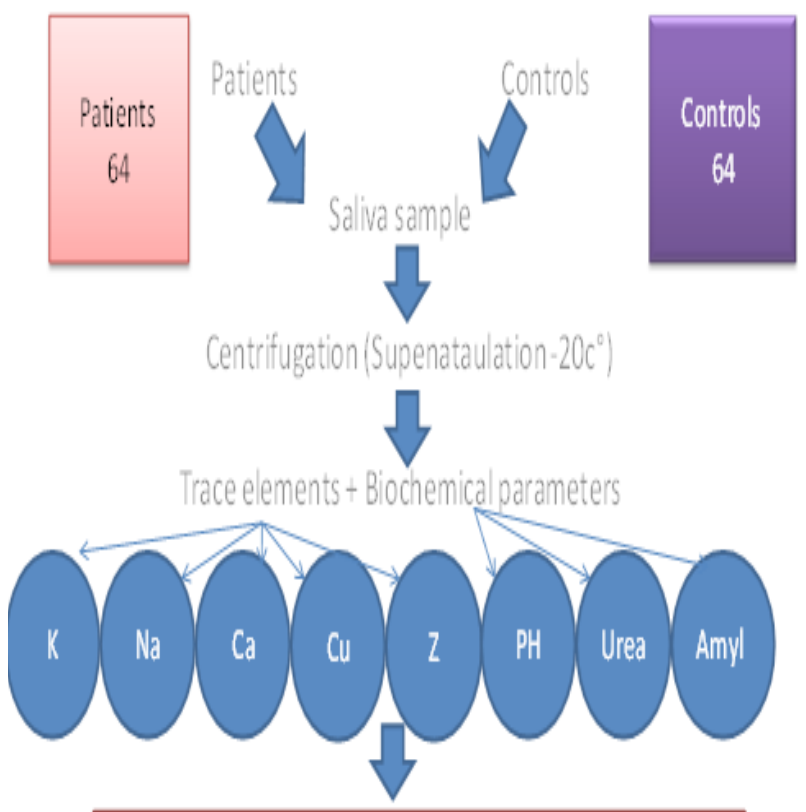

Comparison between patients and controls

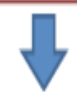

Assessment of salivary parameters in patients and controls

Figure 1: A schematic presentation of study design.

\section{Materials used for salivary parameters estimation 1-Salivary Urea reagent}

Table1:Randox kit.

\begin{tabular}{|c|c|}
\hline Materials & Concentration \\
\hline GAMMA GT (Liquid) (Mono Reagent) & $0.05 \mathrm{mmol} / \mathrm{LL}$ \\
\hline CARBOXY (RX Daytona ${ }^{\mathrm{TM}}$ ) & $0.05 \mathrm{mmol} / \mathrm{L}$ \\
\hline Distal water & $1 \mathrm{mmol} / \mathrm{L}$ \\
\hline
\end{tabular}

\section{2-Salivary Amylase reagent}

Table 2: Reagent of $\alpha$-Amylase.

\begin{tabular}{|c|c|}
\hline Materials & Concentration \\
\hline MES PH 6 & $100 \mathrm{mmol} / \mathrm{L}$ \\
\hline 2-chloro-4-nitrophe- & $2.25 \mathrm{mmol} / \mathrm{L}$ \\
nyl- $\alpha$-D-maltotrisoside & $350 \mathrm{mmol} / \mathrm{L}$ \\
\hline Sodium chloride & $6 \mathrm{mmol} / \mathrm{L}$ \\
\hline Calcium acetate & $900 \mathrm{mmol} / \mathrm{L}$ \\
\hline Potassium thiocyanate & $0.9 \mathrm{gm} / \mathrm{L}$ \\
\hline
\end{tabular}




\section{3-Salivary PH \\ 4-Salivary Potassium, Sodium, Zinc, Calcium and Copper}

These parameters were tested through Atomic absorption Spectrophotometer use of special reagents of the device.

\section{RESULTS}

\section{Biochemical parameters and trace elements 1. Salivary Potassium}

Mean salivary potassium levels significantly $(\mathrm{p}<0.001)$ lowered in ESRD patients $(0.2 \pm 0.03)$ than control group $(0.3 \pm 0.02)$.

\section{Salivary Sodium}

The mean sodium level in saliva was highly significant lowered in $84.4 \%$ of patients with ESRD patients $(0.4 \pm 0.06)$ as compared to control group $(0.7 \pm)$.

The results of the present study also showed that the mean salivary sodium level was significantly higher $(\mathrm{p}<0.05)$ in male $(0.52 \pm 0.02)$ than females $(0.31 \pm 0.01)$ with ESRD.

\section{Salivary Calcium}

The results showed that the mean salivary Calcium level is low $67.2 \%$ of ESRD patients $1.7 \pm 0.2 \mathrm{ml} / \mathrm{dl}$ as compared to zero in control group $(3.076 \pm \cdot, \varepsilon r \cdot)$ with highly significant differences salivary calcium level between ESRD patients and control group $(\mathrm{p}<\bullet, \cdot 1)$.

The current results revealed that the mean salivary calcium level was significantly higher $(\mathrm{p}<0.05)$ in males $(1.9 \pm 0.82)$ than females $(1.5 \pm$ $0.61)$ with ESRD.

\section{Salivary Copper}

The mean salivary Copper level is low in $92 \%$ of ESRD patients $(1.8 \pm 0.4 \mu \mathrm{gm} / \mathrm{dl})$, when compared to $4.8 \%$ control group. A highly significant difference was observed insalivary Copper level between ESRD patients and controls $(\mathrm{p}<0.01)$.

\section{Salivary Zinc}

The mean salivary Zinc level of ESRD patients was $4.5 \pm 1.3 \mu \mathrm{gm} / \mathrm{dl}, 7.8 \%$ of them had low salivary Zinc level and mean salivary Zinc level of controls was $3.9 \pm 1.5 \mu \mathrm{gm} / \mathrm{dl}$, all of controls had normal salivary Zinc level. There was a statistically significant difference in salivary Zinc level between ESRD patients and controls $(\mathrm{p}=0.049)$.

\section{Salivary PH}

The mean PH of ESRD patients was $7.9 \pm 0.4$, most of ESRD patients had basic salivary PH, 4 ESRD patients had neutral salivary $\mathrm{PH}$ and two patients had acidic $\mathrm{PH}$, on other hand, mean salivary $\mathrm{PH}$ of controls was $7.8 \pm 0.3$, the majority of controls had basic salivary PH and only 4 controls had neutral PH.
No significant difference in salivary $\mathrm{PH}$ was observed between ESRD patients and controls $(p=0.285)$.

\section{Salivary Urea}

The mean salivary Urea of ESRD patients was $0.6 \pm 0.2$; range was 1.1 , while mean of salivary Urea for controls was $0.2 \pm 0.06$ with range as 0.2 . There was a highly significant difference in salivary urea between ESRD patients and controls $(p<0.01)$.

\section{Salivary Amylase}

The mean of salivary Amylase among ESRD patients was $61467.8 \pm 29943$. For controls, mean salivary Amylase was $43721.8 \pm 14131.6$. There was a highly significant difference in salivary Amylase between ESRD patients and controls $(p=\mathbf{0 . 0 3 0})$.

\section{DISCUSSION}

Wide range of oral manifestations have been found among ESRD patients like, gingivitis, xerostomia, ammonia-like smell, mucosal pallor and lesions, tooth mobility, malocclusion and high risk of dental erosion caused by frequent regurgitation. Systemic and salivary imbalance caused by chronic renal failure, multiple medications, vomiting and low self-hygiene may affect oral health in these patients (8).

The Current results found that half of ESRD patients had dialysis duration more than one year. This finding came in agreement with finding of Al Wakeelet al (2002) ${ }^{(8)}$ in Saudi Arabia who reported that mean duration of dialysis 5.7 years. The recovery of renal function in patients with prolonged hemodialysis is reported to be a relatively uncommon occurrence. Large observational cohorts of ESRD patients started on long-term hemodialysis from different parts of the world reported renal recovery rates of as low as $1 \%$ $2.4 \%{ }^{(9)}$.

In this study, Hypertension was present among $64.1 \%$ of ESRD patients. Also this finding is consistent with results of Silva et al $(2012)^{(10)}$ who observed that HT is the main cardiovascular risk factor associated with Brazilian ESRD.

Current study revealed that salivary Potassium level in ESRD patients was significantly lower than salivary Potassium level of control group. In contrast to study of Manley et al (2012) ${ }^{(11)}$ who were found significant higher salivary potassium among Australian ESRD patients.

The current studyresults found highly significant difference $(p<0.001)$ in salivary Calcium levels between ESRD patients and control, while Abdulla et al(2012)didn't find significant difference in the salivary Calcium between ESRD patients and control 
groups.

Current results about lower salivary Calcium in ESRD patients are inconsistent with results of Manley et al (2012) $)^{(11)}$ in Australia that didn't find significant difference in salivary Calcium between ESRD patients and healthy controls. The difference may be due to that ESRD patients in Austraian study were not on pre-hemodialysis phase and our patients were on post-hemodialysis phase.

Current results revealed that there were highly significant differences in the mean salivary Copper of ESRD patients. Our study was the first study exploring salivary Copper among ESRD patients in Iraq. This findings are close to results of Abdellatifet al (2011) ${ }^{(12)}$ in Egyptwho observed deficient salivary Copper in ESRD children.

The results of the present study appeared that the salivary PH of ESRD patients and control were basic (mean $=7.9,7.8$ ) respectively with no significant difference between the two groups regarding $\mathrm{PH}$. This finding is consistent with the findings of results of(Bayraktaret al, 2009) ${ }^{(13)}$ inTurkey who found that highly significant association between ESRD patients and increased salivary PH.Fortunately, the high salivary PH in ESRD patients decreases prevalence of dental caries among them ${ }^{(14)}$.

According to mean of means salivary Urea there was a highly significant difference between ESRD patients and control group regarding salivary Urea $(p<0.001)$. This is similar to findings of previous Iraq study (Abdullaet al, 2012)who showed that highly significant difference between patients that includes ESRD, hemodyalis and controls regarding salivary urea. Also Alietal(2013) ${ }^{(15)}$ in Indiareported highly significant increaseof salivary Urea among ESRD patients.

The findings of this study were clarified that salivary Amylase of ESRD patients significantly higher than mean salivary Amylase of control group. This is similar to results of (Tomáset al, 2008) ${ }^{(1)}$ in Portugal patients with chronic renal failure (ESRD) compared to healthy controls when measured salivary biochemical parameters of both groups and found highly significant difference in salivary Amylase level between ESRD and control groups.

\section{REFERENCES}

1. Tomás, I. Marinh, J. S. Limeres, J. Santos, M. J.; Arau, L. and Diz, P. Changes in salivary composition in patients with renal failure. Archives of oral biology2008; 53: 528-532.

2. Baum, BJ. Yates, JR., Srivastava, S.; Wong, DT., Melvin, JE. Scientific frontiers: emerging technologies for salivary diagnostics. Adv Dent Res 2011; 23: 360-368.

3. Atassi, F. Oral home care and the reasons for seeking dental care by individuals on renal dialysis. J Contemp Dent Pract, 2002; 3: 31-41.

4. Proctor, R., Kumar, N., Stein, A., Moles, D., Porter, S. Oral and dental aspects of chronic renal failure. J Dent Res 2005; 84: 199-208.

5. Marakoglu, I., Gursoy, U. K., Demirer, S., Sezer H. Periodontal status of chronic renal failure patients receiving hemodialysis. Yonsei Med J 2003; 44: 648-652.

6. Hadi, B. A. A., Al-Jubouri, R. H. Salivary and plasma analysis of oxidative stress biomarkers in end stage renal failure patients. J BaghColl Dentistry2011; 23: 46-50.

7. Bots, C. P., Brand, H. S., Poorterman, J. H. G., ValentijnBenz, M., ter Wee, P. M., Veerman, E. C. I., et al. Oral and salivary changes in patients with end stage renal disease (ESRD): a two year follow-up study. British Dental Journal 2007; 202: E7.

8. Al Wakeel, J.S., Mitwalli, A.H., Al Mohaya, S., Abu-Aisha, H., Tarif, N., Malik, G.H., Hammad, D.Morbidity and mortality in ESRD patients on dialysis. Saudi J Kidney Dis Transpl2002; 13(4):473-7.

9. Chu, J.K., Folkert, V.W.Renal function recovery in chronic dialysis patients. Semin Dial2010; 23: 606-613.

10. Silva, L.S., Oliveira, R.A., Silva, G.B., Lima, J.W., Silva, R.P., Liborio, A.B., et al.Cardiovascular disease in patients with end-stage renal disease on hemodialysis in a developing country. Saudi J Kidney Dis Transpl2012; 23(2):262-6.

11. Manley, K.J.,Haryono, R.Y., \&Keast, RSJ. Taste changes and saliva composition in chronic kidney disease. Renal Society of Australasia Journal 2012; 8(2): 56-60.

12. Abdellatif, A.M., Hegazy, S.A., Youssef, J.M. The oral health status and salivary parameters of Egyptian children on hemodialysis. Journal of advanced research2011; 2: 313-318.

13. Bayraktar, G., Kurtulus, I., Kazancioglu, R., Bayramgurler, I., Cintan, S., Bural, C., Bozfakioglu, S., Issever, H., Yildiz, A. Oral health and inflammation in patients with End-Stage Renal failure. Perit Dial Int2009; 29: 472-479.

14. Al-Nowaiser, Roberts, G.J., Trompeter, R.S., Wilson, M., Lucas, V.S. (2003). Oral health in children with chronic renal failure. PediatrNephrol 18:39-45.

15. Ali, S.P., Gupta, J., Nagesh, K.S., Iyengar, A.R. Blood Urea \& Salivary (2013). Urea levels in End Stage Renal Failure. Indian Medical Gazette. 373-375

16. Abdulla, H. I.; Al-Kotany, M. Y., and Mahdi, K. A. (2012). Assessment of oral manifestations of patients with renal failure undergoing hemodialysis by serum a salivary biomarkers. MDJ, 9: 118-129. 